University of Nebraska - Lincoln

DigitalCommons@University of Nebraska - Lincoln

6-1997

\title{
Gregarina triboliorum (Eugregarinida: Gregarinidae) n. sp. from Tribolium confusum and Resolution of the Confused Taxonomic History of Gregarina minuta Ishii, 1914
}

\author{
Stephanie Watwood \\ Woods Hole Oceanographic Institution, swatwood@whoi.edu \\ John J. Janovy Jr. \\ University of Nebraska - Lincoln, jjanovy1@unl.edu \\ Erica Peterson \\ University of Nebraska - Lincoln \\ Mary Ann Addison \\ University of Nebraska - Lincoln
}

Follow this and additional works at: https://digitalcommons.unl.edu/bioscijanovy

Part of the Parasitology Commons

Watwood, Stephanie; Janovy, John J. Jr.; Peterson, Erica; and Addison, Mary Ann, "Gregarina triboliorum (Eugregarinida: Gregarinidae) n. sp. from Tribolium confusum and Resolution of the Confused Taxonomic History of Gregarina minuta Ishii, 1914" (1997). John Janovy Publications. 47.

https://digitalcommons.unl.edu/bioscijanovy/47

This Article is brought to you for free and open access by the Papers in the Biological Sciences at DigitalCommons@University of Nebraska - Lincoln. It has been accepted for inclusion in John Janovy Publications by an authorized administrator of DigitalCommons@University of Nebraska - Lincoln. 


\title{
GREGARINA TRIBOLIORUM (EUGREGARINIDA: GREGARINIDAE) N. SP. FROM TRIBOLIUM CONFUSUM AND RESOLUTION OF THE CONFUSED TAXONOMIC HISTORY OF GREGARINA MINUTA ISHII, 1914
}

\author{
Stephanie Watwood, J. Janovy, Jr., Erica Peterson, and Mary Ann Addison \\ School of Biological Sciences, University of Nebraska-Lincoln, Lincoln, Nebraska 68588-0118
}

\begin{abstract}
The septate gregarine parasites of flour beetles (Tribolium spp.) include Gregarina minuta Ishii, 1914, a relatively small species in which both primite and satellite possess an obvious protomerite, and a larger species that lacks the satellite protomerite. The latter species has been placed in the genera Didymophyes and Hirmocystis by various authors, but studies reported here demonstrate that this species, herein described as Gregarina triboliorum, exhibits early pairing and produces oocyst chains, both characteristics of the genus Gregarina. The oocysts of this new species are described for the first time. In addition, experimental infections using oocysts from single gametocysts reveal that oocyst chain number is variable but is typically 1,2 , or 4. Prior experiments involving a related beetle, Tenebrio molitor, demonstrated extreme host specificity within the 4 Gregarina species parasitizing larval and adult hosts. However, $G$. triboliorum is not limited either stadially or specially, infecting both adults and larvae of Tribolium confusum and Tribolium castaneum.
\end{abstract}

Ishii (1914) described Gregarina minuta, a eugregarine parasite, from the intestine of Tribolium ferrugineum (Coleoptera: Tenebrionidae), basing the generic designation on the presence of an ovoid protomerite, a single spherical karyosome, and spherical gametocysts. Since this original description, the gregarines of Tribolium sp. have made a nomenclatural journey through 3 genera, primarily because dehiscence and oocyst morphology have never been subsequently reported. Ishii (1914) included organisms with 3 different morphologies under the name $G$. minuta: (1) relatively large $(188 \mu \mathrm{m})$ biassociative parasites lacking a protomerite on the satellite, (2) smaller (118 $\mu \mathrm{m})$ biassociative gregarines displaying the protomerite in the satellite, and (3) a single unpaired "sporont" (27-120 $\mu \mathrm{m})$. In addition, Ishii (1914) admitted that the protomerite of the satellite "was not infrequently hidden from view," suggesting the possibility of more than 1 species, but attributed the difference to polymorphism, stating that in some associations the satellite protomerite was entirely imbedded in the deutomerite of the primite. Watson (1916) suggested that Ishii (1914) had included 2 different species under the name $G$. minuta and described the gregarine lacking a satellite protomerite as Didymophyes minuta, noting that the absence of the protomerite of the satellite is the chief diagnostic character of the family Didymophyidae, in which there is but 1 genus, Didymophyes. Watson (1916) maintained Ishii's smaller parasite as G. minuta. However, Roy (1989) was unable to distinguish sporoducts on the gametocysts and proposed placing the species lacking the protomerite on the satellite in Hirmocystis because 1 characteristic of this genus is extrusion of oocysts by simple rupture, and thus classified the species as Hirmocystis minuta.

The degree of host specificity displayed by a parasite has both evolutionary and taxonomic significance. Past experimental studies of gregarine infections of hosts within the coleopteran family Tenebrionidae have demonstrated an extreme degree of host specificity, being limited both spatially within the host intestinal tract and stadially within the life cycle (Clopton et al., 1992). The question of host specificity remains important for gregarines because of the enormous diversity of both hosts and parasites and the general lack of experimental studies to

Received 11 July 1996; revised 16 December 1996; accepted 16 December 1996. support taxonomic conclusions (cf. references in Levine, 1988). The original purpose of the present study was to determine whether the extreme host specificity demonstrated by Clopton et al. (1992) for the 4 Gregarina species in Tenebrio molitor was characteristic also of the parasites in Tribolium spp. The morphological similarity of gregarines in Tribolium castaneum adults and larvae, and in Tribolium confusum adults and larvae, makes such a study necessary before the concept of extreme host specificity in tenebrionid gregarines can be generalized. In order to pursue these studies, however, the taxonomic position of the parasites in $T r$. confusum and $T r$. castaneum, especially the species lacking a satellite protomerite, had to be clarified. This goal was accomplished through a series of experimental infections involving oocysts from single gametocysts and local beetle stocks that, at least throughout the course of this research, have been infected with only the parasite species lacking a satellite protomerite, i.e., the one described herein as Gregarina triboliorum. This study was intended to answer 3 questions: (1) do gametocysts from this species dehisce in the same manner as those of other Gregarina species; (2) is oocyst chain number a stable character, and (3) does this species infect both larvae and adults of $T r$. confusum and Tr. castaneum?

\section{MATERIALS AND METHODS}

Two species of flour beetles, Tr. confusum and Tr. castaneum, were taken from research stocks maintained in 230-ml glass bottles at the University of Nebraska-Lincoln. Beetles for these studies were cultured in cotton-plugged $230-\mathrm{ml}$ glass bottles, plastic petri dishes, or cottonplugged $8-\mathrm{ml}$ glass vials, depending on the particular part of the study being conducted. The medium was $49 \%$ (v/v) whole wheat flour, $49 \%$ whole grain rolled oats, and $2 \%$ active yeast. Each petri dish contained approximately $30 \mathrm{ml}$ of this medium; bottles and vials contained proportionately more or less medium, respectively. The thermal sensitivity of the gregarines was used to maintain parasite-free colonies that were kept in an incubator at $38 \mathrm{C}$ (MacDougall, 1942). Stocks started from sterile adults in heat-sterilized medium were also initiated; these stocks usually remained sterile at room temperature outside the incubator for several months and were used in some of the experimental infections as controls so long as they remained uninfected. Infected colonies were maintained at room temperature (approximately $25 \mathrm{C}$ ) with their petri dishes separated by host species in plastic shoeboxes.

In an initial set of experiments, dust from infected colonies was used as a source of oocysts. Experimental infections were conducted in 8-ml vials. Ten adult or 10 larval beetles were placed into the vial with $2 \mathrm{ml}$ of infective dust, and the vials were plugged with cotton. One or 2 of the beetles in each vial were dissected every $24 \mathrm{hr}$ to determine the rate 
of parasite growth and the time of maximum gamont pairing. The day when the greatest proportion of gregarines was large and paired was assumed to be the optimal day for beetle isolation and harvesting of gametocysts.

For gametocyst collection, beetles were isolated in plastic in vitro fertilization dishes with a moist piece of paper towel placed in the center well. Approximately $24 \mathrm{hr}$ postisolation, the beetles were removed and the frass was examined for the presence of gametocysts. The gametocysts were then picked up by a moist single-hair brush and placed on an $11-\mathrm{mm} \times 11-\mathrm{mm}$ coverslip in the center of another in vitro fertilization dish. Water was added to the outer moat, and the gametocysts were checked for sporulation at 24-hr intervals thereafter. A sample of oocysts from these sporulated gametocysts was retained for measurement. A drop of glycerin was placed on a slide, and the coverslip containing the sporulated gametocyst was inverted onto this preparation (Clopton et al., 1991). The oocysts were then measured under oil immersion $(1,000 \times)$. All sporulated gametocysts were labeled according to date of isolation, host life cycle stage (larva or adult) and species ( $T r$. castaneum or $\operatorname{Tr}$. confusum), and the number of oocyst chains produced.

Host specificity experiments examined the ability of the gregarines to infect heterologous host species and life cycle stages. The experimental design required (1) a time- 0 uninfected homologous control (to determine whether the beetle source was uninfected), (2) a time- 0 uninfected heterologous control, (3) a time-t uninfected homologous control (to determine whether the control beetles remained uninfected), (4) a time-t uninfected heterologous control, (5) a positive, experimentally infected, homologous control (to determine whether oocysts were viable), and (6) the heterologous, experimentally infected hosts. Groups 14 were either set up in vials at the time of the experiments from uninfected stocks or taken from uninfected stocks as needed at the start and conclusion of infection experiments.

Both short- and long-term experiments were conducted. Experiments were considered valid only if groups 1-4 remained uninfected and the positive homologous control, group 5, became infected. A total of 29 experimental infections were attempted in the host specificity studies with various combinations of parasite sources and host and stadium targets. Of these, 26 yielded usable information, 2 were were invalid because of noninfected positive controls, and 1 was invalid because of infected negative controls. For each short-term experiment, 5 adult or larval beetles were placed in an 8-ml vial containing a moistened piece of oatmeal and oocysts of known origin. Hosts were dissected 8 days postexposure, and gregarine presence was recorded. The heritable stability of oocyst chain number was studied in long-term experiments by exposing noninfected beetles to oocysts from single gametocysts of known oocyst chain number. Three months later, gametocysts from the progeny of these exposed beetles were isolated, and oocyst chain number was recorded for those that sporulated.

For the taxonomic studies, measurements were taken (in micrometers) of 701 individual gregarines from 50 adult $T r$. confusum, 390 from 31 larval $T r$. confusum, 168 from 40 adult $T r$. castaneum, and 178 from 23 larval $T r$. castaneum, all in water, from freshly dissected hosts. For the description, measurements of gamonts are only from associated pairs. The gamont analysis involved 443 parasites from adult $T r$. confusum, 156 from larval $T r$. confusum, 114 from adult $T r$. castaneum, and 102 from larval Tr. castaneum. Protomerite and deutomerite lengths and widths were compared using a 1-way ANOVA, with the same attribute, e.g., primite deutomerite length, being compared across the 4 host groups (adult $T r$. confusum, larval $T r$. confusum, adult $T r$. castaneum, larval $T r$. castaneum). Measurement ratios of 258 unpaired trophozoites are also given in the species description. Ratios of the various measurements were calculated individually, then means, standard deviations, and ranges were determined on the sample of individual ratios.

Type material was simultaneously fixed and stained in Semichon's aceto-carmine, dehydrated through an ethyl alcohol series, cleared in xylene, and mounted in Canada balsam (Clopton, 1995a, 1995b). Statistical analysis was performed with the use of FieldStat (Clopton and Janovy, 1991). Terminology for life cycle stages is consistent with that used by Clopton et al. (1991) for descriptions and redescriptions of the gregarines parasitizing $T$. molitor. Terminology for shapes of planes is consistent with that suggested by the Systematics Associate Committee for Descriptive Biological Terminology (Anonymous, 1962a, 1962b). Drawings were made with the aid of a camera lucida or, in the case of oocysts, with the use of acetate tracings from a video screen showing oocysts as seen under oil immersion. Figure 1a is from the deposited type specimen; Fig. lb-h were taken from fresh dissections in Tenebrio muscle saline (Belton and Grundfest, 1962) of adult Tr. confusum.

\section{DESCRIPTION}

Gregarina triboliorum n. sp.

(Figs. 1, 2)

Diagnosis: Gregarinidae with characters of the genus Gregarina as defined by Dufour (1828) and revised by Watson (1916), Kamm (1922), and Levine (1979): Sporonts biassociative, simple globular, conical, button-shaped or cylindrical papillalike epimerite, gametocyst dehiscence by sporoducts, and doliform, navicular, or spherical oocysts.

Trophozoites: Generally with protomerite. Some small unpaired trophozoites with relatively large, refractile granules, especially in the posterior portion of the cell (Fig. 1f); protomerites broadly ovate when present; some trophozoites with truncated posterior ends (Fig. 1h). Attached trophozoites rarely if ever seen in either fresh dissections or stained smears. Epimerite an elliptical or broadly elliptical button or ovate cone on small $(20-30 \mu \mathrm{m})$ trophozoites (Fig. 1e). Size of freshly isolated, living unpaired trophozoites (in micrometers; mean (standard deviation), range, $n$ ): total length (TL) 71.4 (33.4), 28.8-201.6, 258; protomerite length (LP) $6.8(4.5), 0-19.2,258$; protomerite width (WP) 7.0 (4.8), 0-19.2, 258; deutomerite length (LD) 64.6 (33.1), 19.2-192, 258; deutomerite width (WD) 25.7 (12.0), 9.6-76.8, 258. Ratios of measurements: LP/LD 0.13 (0.12), 0-0.67, 258; LP/TL 1.09 (0.08), 0-0.40, 258; LD/TL 0.89 (0.09), 0.60-1.00, 258; WP/WD $0.32(0.26), 0-1.00$ 258.

Gamonts in association: Pairing is early and asynchronous; smallest paired primite 28.8 and associated satellite 19.2 . The primites are composed of a circular or transversely broadly elliptical protomerite and a narrowly oblong deutomerite (Fig. 1a). Size of freshly isolated, living primites (in micrometers; mean (standard deviation), range, n): LP 8.9 (4.4), 0-19.2, 443; WP 8.9 (4.2), 0-19.2, 443; LD 97.6 (52.7), 28.8 249.6, 443; WD $30.4(12.4), 9.6-86.4,443$. The satellite lacks a protomerite at all stages of development (Fig. 1a', b, c) and is composed of a narrowly oblong deutomerite, length (LD) (of satellites paired to primites) 95.8 (40.6), 19.2-240.0, 443; width (WD) 29.8 (13.6), 9.696,443 . Ratios of primite measurements: LP/LD $0.10(0.07), 0-0.60$, 443; LP/TL 0.09 (0.05), 0-0.38, 443; LD/TL 0.91 (0.05), 0.63-1.00, 443; WP/WD $0.33(0.20), 0-1.50,443$. Ratio of satellite measurements: WD/LD $0.34(0.15), 0-1.67,443$. Nucleus is approximately circular, $9.6 \times 9.2$, in living specimens but transversely elliptical with wide dimension oriented across the cell in stained smears. Nucleus located medially in primite, slightly anterior to midline in satellite.

Gametocysts: Recently shed gametocysts have a clear to translucent wall and are spherical, diameter 63.2 (6.7), 48.0-76.8, 38. Gametocysts shed and stored under moist conditions sporulate in $24-48 \mathrm{hr}$, forming 1,2 , or 4 oocyst chains.

Dehiscence: One, 2 , or 4 oocyst chains are extruded, evidently through sporoducts; chains separate from the gametocyst ghost upon dehiscence. When exsporulation is allowed to occur in glycerin, cyst wall integrity is preserved, gaps in the wall can be observed, and the oocyst chain remains intact although it is folded back and forth upon itself

Oocysts: Doliform, typically with dorsal concavity; length 4.9 (SD $=0 ; \mathrm{n}=25)$, width $3.6(0.2,25)$, thickness $2.4(0.2,10)$.

Type host: Adult Tr. confusum Jacquelin du Val, 1868; confused flour beetle.

Other hosts: Larval Tr. confusum and Tr. castaneum (Herbst, 1797) Macleay, 1825; red flour beetle, both larvae and adults.

Type locality: School of Biological Sciences, University of Nebraska-Lincoln, Lincoln, Lancaster County, Nebraska.

Etymology: The specific epithet, triboliorum, is derived from the genus of the host beetles, Tribolium.

Type specimens deposited: Hapantotype (1 slide) deposited in the $\mathrm{H}$. W. Manter Laboratory of Parasitology, University of Nebraska State Museum, UNSM/HWML \#39114; paratypes (3 slides) from adult $\mathrm{Tr}$. confusum, HWML \#39115; from larval Tr. castaneum (2 slides), HWML \#39116; and from adult Tr. castaneum (2 slides), HWML \#39117. 


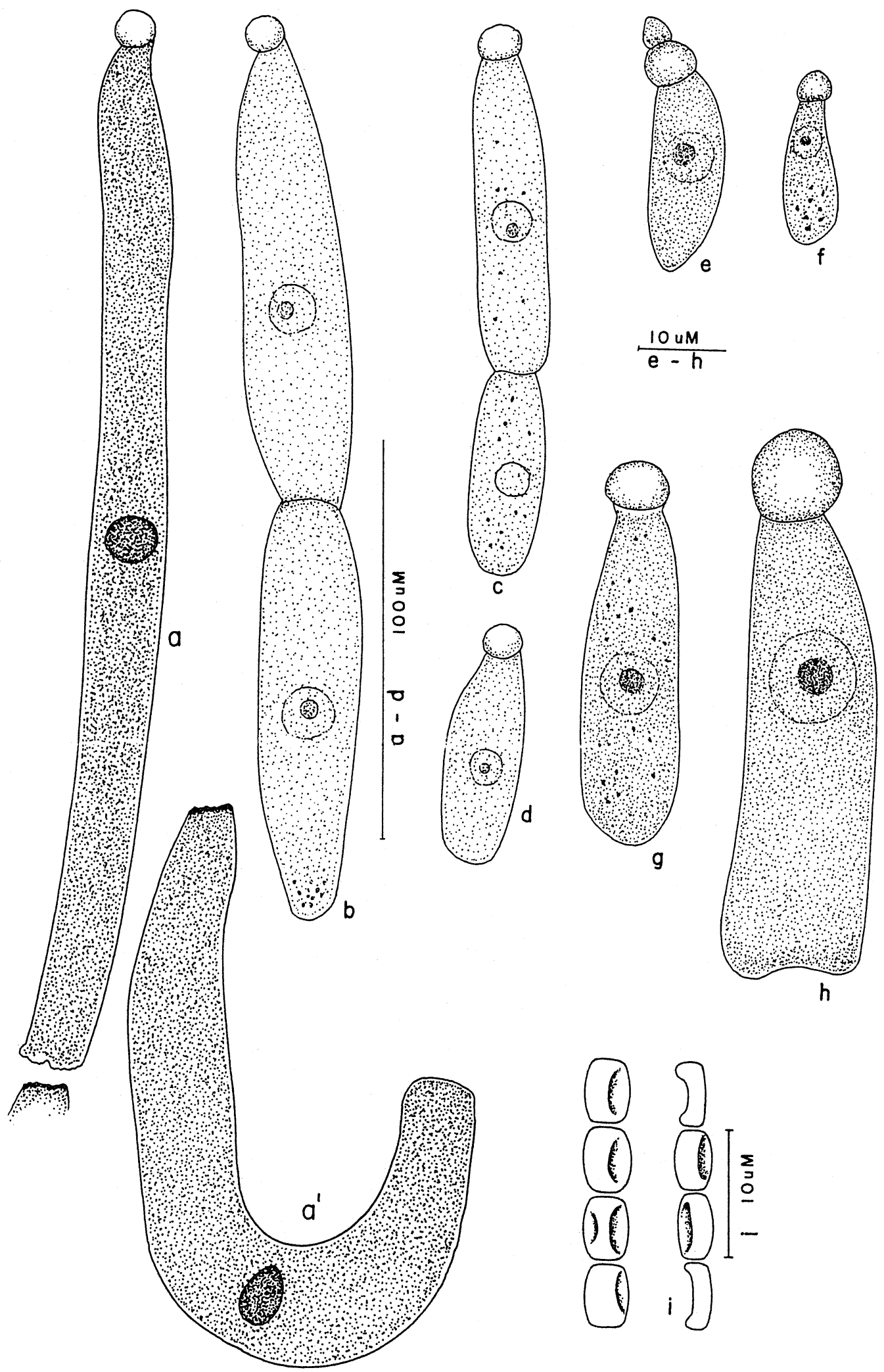

FIGURE 1. Gregarina triboliorum n. sp. a, a' are paired primites and satellites, respectively, drawn with the aid of the camera lucida from the type slide; b-c, smaller gamonts showing cytoplasmic granules and pairing of individuals of different ages; d, h, small trophozoites showing primite characters; e, trophozoite with epimerite; f, very small individual with posterior cytoplasmic granules; i, 2 sections of an oocyst chain. Scale bars are labeled according to the figures to which they apply. 


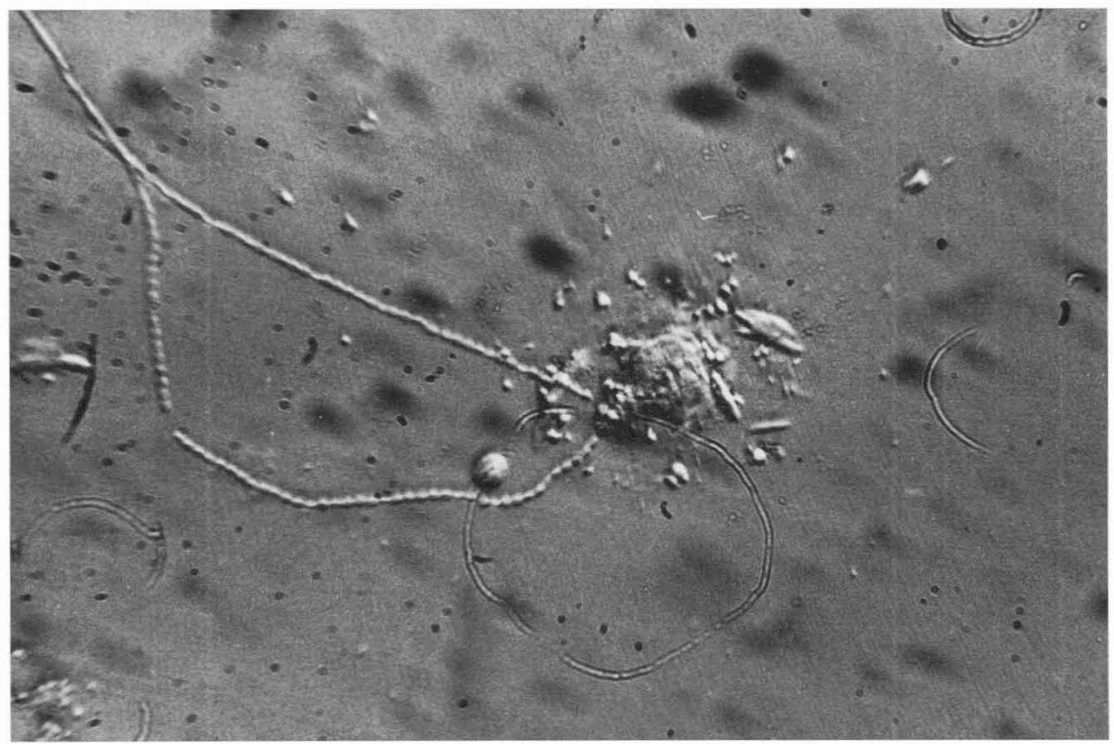

FIGURE 2. Photomicrograph of dehiscence in Gregarina triboliorum gametocyst, showing extruded spore chains.

\section{Remarks}

The consistent lack of a protomerite on the satellite of the gregarine under present study supports the interpretation that the absent protomerite is not merely an aberration but rather a distinct and stable morphological trait, possibly one manifested immediately upon association of the gamonts, on the basis of the observation that virtually all smaller trophozoites have protomerites. The presence of unpaired individuals with a shoulderlike profile immediately posterior to the protomerite (Fig. 1d, h) or with truncated posterior ends (Fig. 1h) suggests gamont differentiation as well as pairing occurs early (these individuals are presumptive primites). Young trophozoites sometimes have relatively large refractile granules in their posterior cytoplasm (Fig. 1f), and somewhat older trophozoites or gamonts may have somewhat smaller, but still refractile, granules scattered throughout the cytoplasm (Fig. 1c, g). These granules are never needlelike, however, as described for Didy mophyes sp. (Lee et al., 1985).

Gregarina triboliorum is the larger of the 2 gregarines originally included in Ishii's (1914) description of $G$. minuta from $T r$. ferrugineum (=castaneum), such description being made possible by the experimental work on host specificity, dehiscence, and oocyst chain number (below). Although in the family Didymophyidae the satellite septum is slowly resorbed, thus resembling $G$. triboliorum, didymophyid oocysts are emitted in packets through a single very long sporoduct and consist of a loose epispore and elliptical endospore (Lee et al., 1985). Gregarina triboliorum oocysts are released in long chains through 1,2 , or 4 sites and structurally are distinctly typical of Gregarina sp. oocysts (Clopton et al., 1991; Figs. 1i, 2), observations that invalidate Watson's (1916) placement of $G$. triboliorum in the genus Didymophyes. Roy's (1989) classification is incorrect because gametocysts of the genus Hirmocystis dehisce by simple rupture and gamonts associate in long chains (Lee et al., 1985); virtually all gamonts of $G$. triboliorum associate in pairs. Therefore, Ishii's (1914) original description of G. minuta must be restricted to the smaller of the 2 parasites, that is, the one exhibiting a persistent satellite protomerite, whereas the larger, consistently lacking a satellite protomerite, is redescribed as $G$. triboliorum.

In comparison with Gregarina crassa Ishii, 1914, from $T r$. ferrugineum (=castaneum), the only other described Gregarina species lacking a satellite protomerite, $G$. triboliorum is on average half as wide as the specimen presented by Ishii. Ishii (1914) also reported G. crassa as possessing a very dense endocyte in the deutomerite, giving the gregarine a dark brown to black appearance, whereas $G$. triboliorum has a clear, nondense endocyte. Watson (1916) stated that because Ishii presented only "one indistinct figure" and the measurements from 1 specimen, she was unable to determine the taxonomic placement of this species or even determine if the satellite protomerite was truly absent; we agree with Watson (1916). Other Gregarina spp. described from tenebrionids include Gregarina tokonoi Obata, 1953 from Uloma latimanus, G. pumila Hoshide, 1958, and G. tenebrionella Watson, 1915 (from "Tenebrionidae sp. larva and adult" and "larva of Tenebrionidae," respectively); all differ from $G$. triboliorum by the presence of a protomerite in the satellite.

There was no significant difference in average primite protomerite length, or in primite deutomerite length or width, between the measured gregarines from $T r$. confusum adults, $T r$. confusum larvae, $T r$. castaneum adults, and $T r$. castaneum larvae $(F=1.13$; df $=3,811$ for protomerite length; $F=0.73$, df $=3,811$ for primite deutomerite length; $F=0.57$, df $=3,811$ for primite deutomerite width). There was a significant difference in primite protomerite widths $(F=16.67$, df $=$ 3,811 ), with those from larval $T r$. castaneum being widest (but not significantly different from those in adult $T r$. castaneum), and in satellite deutomerite lengths and widths, with parasites from adult $\mathrm{Tr}$. confusum being the largest $(F=2.88$, df $=3,811$ for lengths; $F=2.75$, df $=$ 3,811 for widths).

\section{DISCUSSION}

\section{Life cycle}

In these studies, optimal gametocyst harvest time, when the greatest proportion of gregarines were large and paired, was 8 days postexposure (Figs. 3, 4). If oocysts are infective immediately upon dehiscence, then generation time, e.g., gametocyst to gametocyst, is approximately 12 days for $G$. triboliorum. As in many natural gregarine infections, hosts from stock cultures contained parasites of various ages and thus various sizes. In the case of $G$. triboliorum, there is a small number of relatively large individuals in the sample (Figs. 5, 6). One interpretation of this observation is that a terminal gametocyte differentiation occurs in which gamonts grow quickly immediately prior to syzygy and gametocyst wall secretion. Such a differentiation would explain the common observation that gregarine infections may be quite heavy whereas gametocyst production is relatively low (Ruhnke and Janovy, 1990). In addition, primites and satellites may not be of equal ages and sizes (Figs. 5, 6). The plot of a large number of size-ranked primites and associated satellites (Figs. 5, 6) reveals pairing "behavior" in gregarines and is potentially useful in future comparative studies. Thus, there are a number of factors, most importantly repeated 


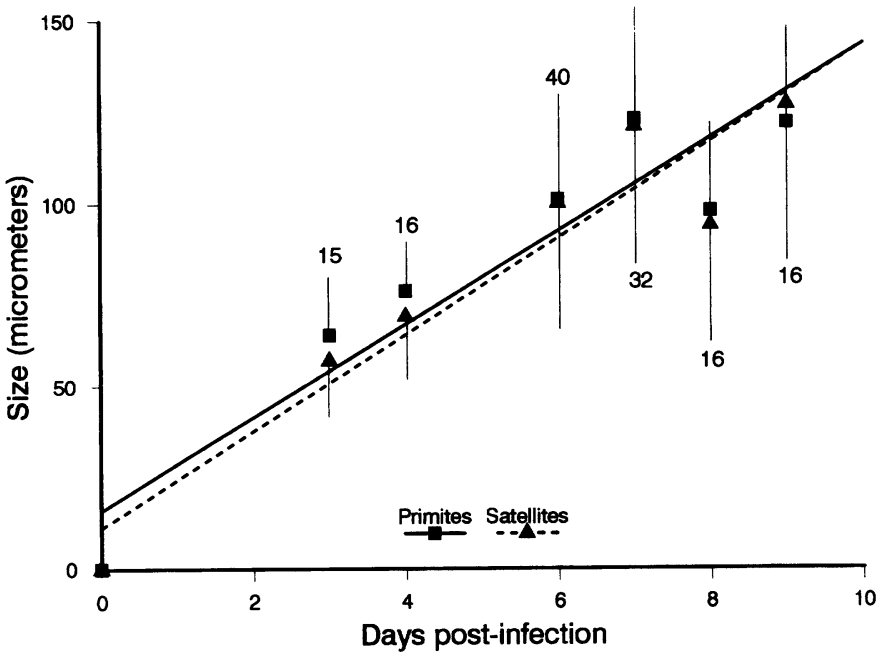

FIGURE 3. Growth of Gregarina triboliorum in adult Tribolium confusum. Squares $(\square)$ represent daily means of total primite length; triangles $(\boldsymbol{\Delta})$ are daily means of satellite lengths. Bars pointing upward are standard deviations of primite lengths; bars pointing downward are standard deviations of satellite lengths. Numbers at ends of bars are the number of associated gamonts averaged for each mean; lines are regression lines for means.

and overlapping infections and pairing of gamonts of unequal ages, working to erode whatever synchrony might be expected in G. triboliorum development. It is likely that, in relatively long-lived insects such as tenebrionids, this asynchrony functions to distribute oocysts more widely in time and space than would be the case in more synchronously developing parasites.

\section{Host specificity}

Oocysts isolated from adult $T r$. confusum infected both larval and adult $T r$. confusum and larval $T r$. castaneum. The oocysts from $T r$. castaneum adults were capable of infecting all life

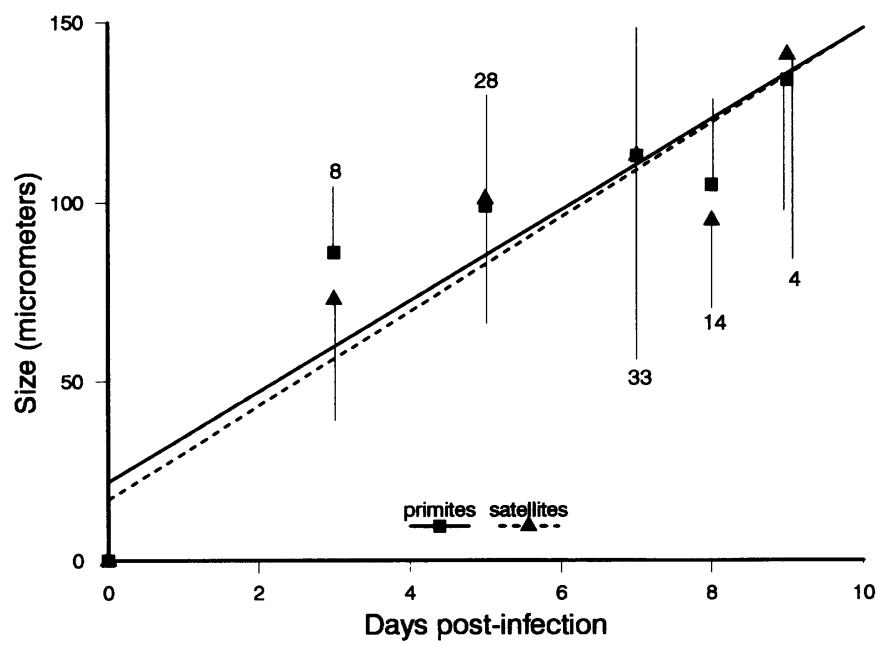

FIGURE 4. Growth of Gregarina triboliorum in larval Tribolium confusum. Squares $(\square)$ represent daily means of total primite length; triangles $(\mathbf{\Lambda})$ are daily means of satellite lengths. Bars pointing upward are standard deviations of primite lengths (except day 9); bars pointing downward are standard deviations of satellite lengths. Numbers at ends of bars are the number of associated gamonts averaged for each mean.

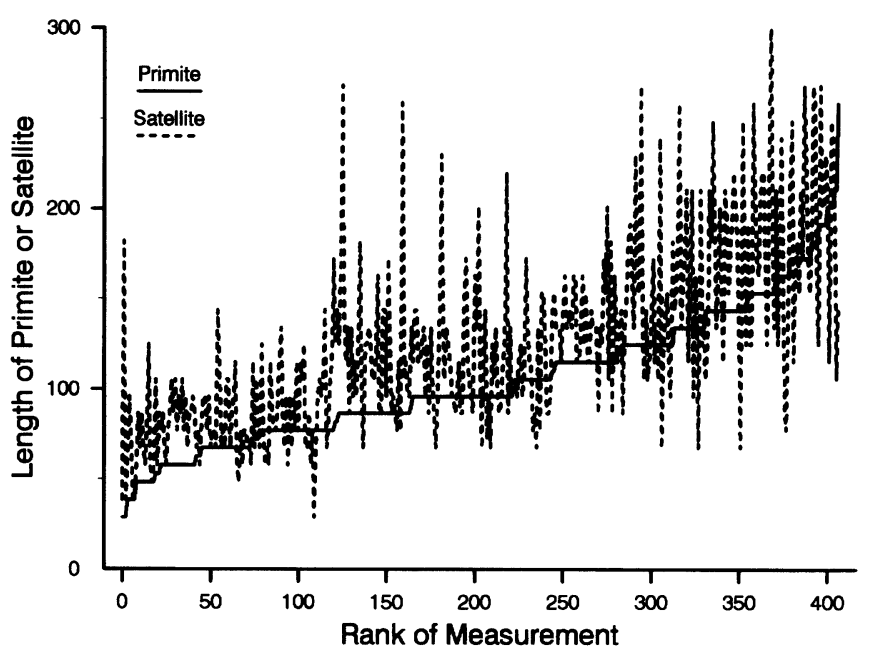

FIGURE 5. Typical age-size makeup of Gregarina triboliorum populations from adult Tribolium confusum in infected stock cultures, as shown by plotting length against ranked primite length for 139 paired gamonts. Solid lines are primite lengths; dashed lines are the associated satellite lengths.

cycle stages of both species. The oocysts from larval Tr. castaneum were capable of infecting larval Tr. confusum and both larval and adult $T r$. castaneum. One question remains unresolved from these experiments, namely the cross-stadia and cross-species infectivity of spores from larval $\mathrm{Tr}$. confusum. In none of the experiments were the positive controls infected when spores from larval Tr. confusum were used. Unsuccessful infections, as observed in uninfected positive controls, were attributed to use of oocysts no longer infective because of advanced age, although it is possible that larval $T r$. confusum do not support the development of infectivity regardless of gametocyst development and dehiscence.

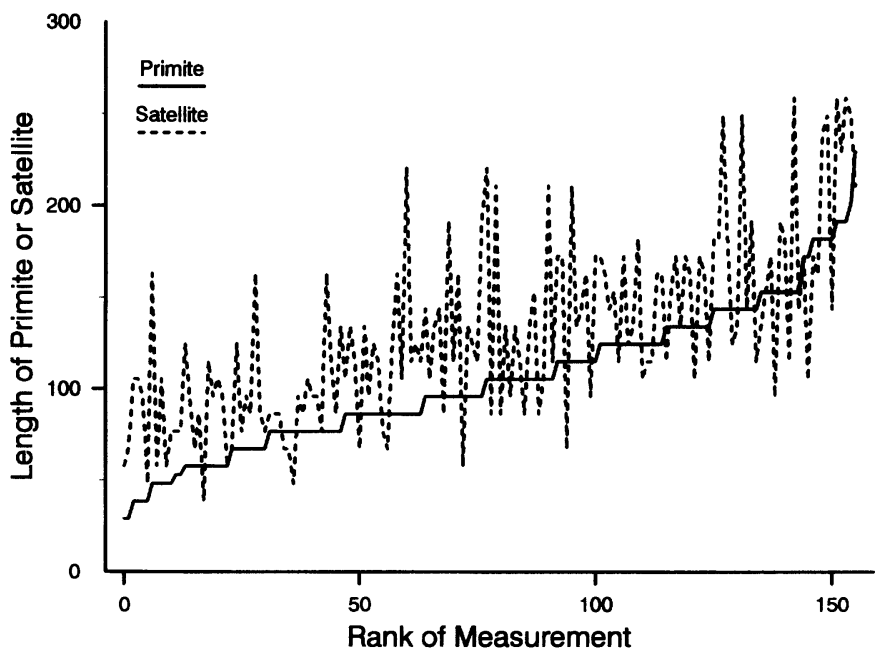

FIGURE 6. Typical age-size makeup of Gregarina triboliorum populations from larval Tribolium confusum in infected stock cultures, as shown by plotting length against ranked primite length for 95 paired gamonts. Solid lines are primite lengths; dashed lines are the associated satellite lengths. 


\section{Stability of spore chain number}

Gametocysts producing 1 and 2 oocyst chains were isolated from beetles initially infected with oocysts from 1-, 2-, and 4-oocyst-chain gametocysts. The single-gametocyst infection results thus demonstrate that the oocyst chain number is not a stable character because the progeny gregarines did not necessarily produce gametocysts with oocyst chain numbers equalling that of the parental generation. This phenomenon suggests that oocyst chain number is not a valid taxonomic character, although the evident restriction in number $(1,2$, or 4 chains) suggests a mechanism that regulates oocyst chain number and thus merits further investigation.

\section{Comparison of tenebrionid gregarine systems}

The experimental host specificity studies using G. triboliorum resolve a question based on morphological data, namely, whether parasites from the 2 host species and life cycle stages are indeed the same species. This capacity of $G$. triboliorum to infect Tribolium across both stadial and special differences demonstrates that the Clopton et al. (1992) model of extreme host specificity based on work with the gregarines of $T$. molitor cannot be generalized to all Gregarina species. Thus, in addition to morphological diversity within the genus Gregarina, this work demonstrates diversity arising from variation in infection strategies. There are approximately 15,000 known species of Tenebrionidae (cf. Delobel and Tran, 1993), more than that of birds and mammals combined. This fact alone suggests a wide range of host-parasite relationships, with the accompanying morphological, developmental, and ecological diversity, within tenebrionid-gregarine systems. A review of the tenebrionidgregarine literature reveals this expectation to be met (Théodoridès, 1955; Levine, 1988). Experimental life cycle studies, such as those reported here, therefore have the potential for greatly expanding our understanding of parasite evolutionary processes, especially with respect to life cycles and parasite adaptations to host niches.

This work has clarified the taxonomic status of gregarine parasites of 2 Tribolium species and demonstrated that there is a range of host specifities among the gregarine parasites of tenebrionid beetles. The first of these contributions is important because of the extensive use of Tribolium spp. in a variety of ecological, genetic, evolutionary, and economic entomology studies. The clarification of parasite taxonomic status, and provision of the morphological criteria by which species can be distinguished, now enables researchers to incorporate gregarines into experimental studies of Tribolium host-parasite systems (cf. Yan and Norman, 1995). The second contribution is important because it illustrates that within a single genus of parasite, infection strategies can range from extreme specialization, as in the gregarines of $T$. molitor, to considerably less specialized, as in G. triboliorum. Such a range of strategies has not generally been considered a factor in host-parasite coevolutionary studies (Brooks and McLennan, 1993). But given the diversity of both coleopterans and gregarines, and the relative ease of doing experimental work on at least some insect-gregarine systems, it is entirely possible that new conceptual contributions will be readily made by investigators interested in working with these systems.

\section{ACKNOWLEDGMENTS}

We thank Dr. Richard E. Clopton for his valuable help and advice regarding this project and manuscript, the Cedar Point Biological Station for use of facilities, and Katie Karnopp for help with data entry.

\section{LITERATURE CITED}

ANONYMOUS. 1962a. Systematics Association Committee for Descriptive Biological Terminology. II. Terminology of simple symmetrical plane shapes (Chart 1). Taxon 11: 145-155.

ANONYMOUS. 1962b. Systematics Association Committee for Descriptive Biological Terminology. IIa. Terminology of simple symmetrical plane shapes (Chart 1a). Taxon 11: 245-247.

Belton, P., AND H. GRUNDFEst. 1962. Potassium activation and K spikes in muscle fibers of the mealworm (Tenebrio molitor). American Journal of Physiology 203: 588-594.

Brooks, D. R., AND D. A. MCLennan. 1993. Parascript: Parasites and the language of evolution. Smithsonian Institution Press, Washington, D.C., 429 p.

Clopton, R. E. 1995a. Domadracunculus janovyi n. gen., n. sp. (Apicomplexa: Actinocephalidae) from adults of Ischnura verticalis (Odonata: Zygoptera) in Texas. Journal of Parasitology 81: 256-260. . 1995b. Leidyana migrator $n$. sp. (Apicomplexa: Eugregarinida: Leidyanidae) from the Madagascar hissing cockroach, Gromphadorhina portentosa (Insecta: Blattodea). Invertebrate Biology 4: 271278. , AND J. JANOVY, JR. 1991. FieldStat stat
Intestine Software, Inc., Lincoln, Nebraska.

. Hotel - - - AND T. J. PERCIVAL. 1992. Host stadium specificity in the gregarine assemblage parasitizing Tenebrio molitor. Journal of Parasitology 78: 334-337.

- T. J. PERCIVAL, AND J. JANOVY, JR. 1991. Gregarina niphandrodes n. sp. (Apicomplexa: Eugregarinorida) from adult Tenebrio molitor (L.) with oocyst descriptions of other gregarine parasites of the yellow mealworm. Journal of Protozoology 38: 472-479.

Delobel, A., AND M. Tran. 1993. Les Coléoptères des denrées alimentaires entroposées dans les régions chaudes. Centre technique de coopération agricole et rurale, Paris, France, 424 p.

Dufour, L. 1828. Note sur la grégarine, nouveau genre de ver qui vit en troupeau dans les intestines de divers insectes. Annales de Sciences Naturelles 13: 366-367.

IsHII, S. 1914. On four polycystid gregarines from the intestine of Tribolium ferrugineum F. Annotationes Zoological Japonenses 8: 435441.

KAMM, M. D. 1922. Studies on gregarines. II. Synopsis of the polycistid gregarines of the world, excluding those from Myriapoda, Orthoptera, and Coleoptera. Illinois Biological Monographs 7: 1-104.

LeE, J. J., S. H. Hutner, AND E. C. BoveE (eds.). 1985. An illustrated guide to the protozoa. Society of Protozoologists, Lawrence, Kansas, $629 \mathrm{p}$.

LEVINE, N. D. 1979. New genera and higher taxa of septate gregarines (Protozoa: Apicomplexa). Journal of Protozoology 26: 532-536. . 1988. The protozoan phylum Apicomplexa, Vol. 1. CRC Press, Boca Raton, Florida, 203 p.

MacDougall, M. M. 1942. A study of the temperature effects on gregarines of Tenebio molitor larvae. Journal of Parasitology 27: 233240.

Roy, K. 1989. Some eugregarines (Sporozoa, Apicomplexa) from the stored fruit beetle, Oryzaephilus mercator Fauv. (Coleoptera) from India. Journal of Protozoology 36: 20-23.

RUHNKE, T. R., AND J. JANOVY, JR. 1990. Life history differences between two species of Gregarina in Tenebrio molitor larvae. Journal of Parasitology 76: 519-522.

THÉODORIDĖS, J. 1955. Gregarines parasites de coleopteres tenebrionides d'Israel. Annales de Parasitology Humaine et Comparée 30: 161173.

Watson, M. E. 1916. Studies on gregarines. Illinois Biological Monographs 2: 213-468.

YAN, G., AND S. NORMAN. 1995. Infection of Tribolium beetles with a tapeworm: Variation in susceptibility within and between beetle species and among genetic strains. Journal of Parasitology 81: 37-42. 